\section{Open access publishing in gastroenterology: good for the researcher and good for the public!}

We wish to highlight the readers the benefits of making their work open access. Advances in the internet have enabled a rapid growth in open access publishing. ${ }^{1}$ However, most scholarly articles still remain behind paywalls. ${ }^{2}$

Open access publishing has numerous benefits. First, open access publishing enables equity of access, with access not dependent on income. Anyone with an internet connection has the opportunity to access research published via the open access route and possibly use this in novel ways not conceived by academic institutions. ${ }^{3}$ It is also important that the public have access to newly published research, as a lot of research activity receives public funding, with a moral obligation for reciprocity. ${ }^{4}$ Open access increases the accessibility of research to developing countries, ${ }^{3}$ which benefits society as a whole. Quality healthcare is often needed the most in these areas, with open access facilitating the worldwide dissemination of research.

Citation metrics can be important aspect of academic impact, with data on citation metrics of open access vs non-open access publications being variable. We reviewed the effect of open access publishing on citation metrics in the field of gastroenterology. We reviewed original research articles in Gut, Gastroenterology and the American Journal of
Gastroenterology (AJG). Publications were cross referenced with the Web of Science database to determine overall citation rates.

Between January 2009 and December 2013, 3057 original research articles were published (Gastroenterology $\quad(n=1431)$, Gut $(\mathrm{n}=732), \quad$ AJG $\quad(\mathrm{n}=894))$. Of these, $154(5.0 \%)$ were open access publications (Gastroenterology $(\mathrm{n}=13)$, Gut $(\mathrm{n}=70)$, AJG $(n=71))$. The proportion of open access publications was different between journals $(p<0.001)$. The variation may have been due to different article processing charges requested by publishers, with open access publication rates known to be variable, dependent on publisher. ${ }^{5}$ Overall, open access publications in the three journals had significantly higher citation rates than non-open access publications (median citation rate: 38.5 vs $33, p=0.044)$, highlighting the benefits of open access publishing in the field of gastroenterology (table 1).

While there are significant benefits of publishing via the open access route, there are potential hurdles preventing widespread adoption. There are questions regarding the quality of scientific journal publishing via the open access route. It has been suggested that if journals collect fees from authors rather than subscribers, journals may accept substandard articles as their income is dependent on the number of articles published. ${ }^{6}$ There have been concerns about predatory journals offering to publish articles for a fee without the rigour of the current peer review system. ${ }^{78}$ However, the methodological quality of studies has been demonstrated to be the same in open access versus non-open access publications. ${ }^{67}$ Cost may also be a barrier. With the Gold Model of open access publishing, the onus of the cost is with authors. However, there are groups aiming to shift the cost of open access publishing to funders or universities. 9

To summarise, the benefits of open access publishing are significant, with our data highlighting the potential benefit on citation metrics for open access publishing in gastroenterology journals. We would recommend our colleagues to publish via this route.

\section{Anupam Rej $\odot$,' Natalie Menic, ${ }^{1}$ Immanuelle Nyamali, ${ }^{2}$ \\ Jason M Punnamkuzhy, ${ }^{1}$ Patrick Whelpdale, ${ }^{1}$ David S Sanders, ${ }^{1}$ Matthew Kurien ${ }^{1}$}

\section{${ }^{1}$ Academic Unit of Gastroenterology, Royal Hallamshire Hospital, Sheffield Teaching Hospital NHS Foundation Trust, Sheffield, UK \\ ${ }^{2}$ Academic Unit of Gastroenterology, Department of Infection, Immunity and Cardiovascular Disease, University of Sheffield, Sheffield, UK}

Correspondence to Dr Anupam Rej, Academic Unit of Gastroenterology, Royal Hallamshire Hospital, Sheffield Teaching Hospital NHS Foundation Trust, Sheffield S10 2JF, UK; anupam. rej@sth.nhs.uk

Contributors MK conceptualised the study. NM, IM, JMP, PW and MK analysed the data. AR, DSS and MK drafted the article. All authors approved the final article.

Competing interests None declared. Patient consent for publication Not required.

\section{Provenance and peer review Not} commissioned; externally peer reviewed. (C) Author(s) (or their employer(s)) 2020. No commercial re-use. See rights and permissions. Published by BMJ.

Check for updates

Table 1 Citation rates across all journals between January 2009 and December 2013

\begin{tabular}{|c|c|c|c|c|c|c|}
\hline \multirow[b]{2}{*}{ Journal name } & \multicolumn{3}{|l|}{ Number of articles } & \multicolumn{2}{|l|}{ Median citation rate } & \multirow{2}{*}{$\begin{array}{l}P \\
\text { value* }\end{array}$} \\
\hline & Open access (\%) & Not open access (\%) & Total & Open access (range) & Not open access (range) & \\
\hline Gut & $70(9.6)$ & $662(90.4)$ & 732 & $47(6-589)$ & $33(0-602)$ & 0.001 \\
\hline Gastroenterology & $13(0.9)$ & $1418(99.1)$ & 1431 & $42(8-79)$ & $38(1-708)$ & 0.863 \\
\hline$A J G$ & $71(7.9)$ & $823(92.1)$ & 894 & $30(1-170)$ & $28(1-251)$ & 0.364 \\
\hline Overall & $154(5.0)$ & $2903(95.0)$ & 3057 & $39(1-589)$ & $33(0-708)$ & 0.044 \\
\hline
\end{tabular}

* Mann-Whitney $U$ test used to compare citation rates between open and non-open access publications. 
To cite Rej A, Menic N, Nyamali I, et al. Frontline Gastroenterology 2020;11:170-171.

Received 10 December 2018

Revised 16 January 2019

Accepted 28 January 2019

Published Online First 18 February 2019

Frontline Gastroenterology 2020;11:170-171.

doi:10.1136/flgastro-2018-101166

\section{ORCID iD}

Anupam Rej http://orcid.org/0000-0002-

1787-2003

\section{REFERENCES}

1 Laakso M, Welling P, Bukvova $\mathrm{H}$, et al.

The development of open access Journal publishing from 1993 to 2009. PLoS One 2011;6:e20961.

2 Khabsa M, Giles CL. The number of scholarly documents on the public web. PLoS One 2014;9:e93949.

3 Tennant JP, Waldner F, Jacques DC, et al. The academic, economic and societal impacts of open access: an evidencebased review. F1000Res 2016;5.

4 Parker M. The ethics of open access publishing. BMC Med Ethics 2013;14.

5 Piwowar $\mathrm{H}$, Priem J, Larivière $\mathrm{V}$, et al. The state of oa: a large-scale analysis of the prevalence and impact of open access articles. PeerJ 2018;6:e4375.

6 Pastorino R, Milovanovic S, Stojanovic J, et al. Quality assessment of studies published in open access and subscription journals: results of a systematic evaluation. PLoS One 2016;11:e0154217.

7 Björk B-C, Solomon D. Open access versus subscription journals: a comparison of scientific impact. BMC Med 2012;10.

8 Sharma H, Verma S. Predatory journals: the rise of worthless biomedical science. $J$ Postgrad Med 2018;64:226-31.

9 Schiltz M. Science without publication Paywalls: cOAlition S for the Realisation of full and immediate open access. PLoS Med 2018;15:e1002663. 